\title{
Study of sex predominance in skin disorders in children aged 1 month to 5 years
}

\author{
Kavthekar S.O. ${ }^{1}$, Chougule A.A. ${ }^{2}$, Kurane A.B. ${ }^{3}$, Kavthekar S.S. ${ }^{4}$ \\ ${ }^{1}$ Dr. Saiprasad Onkareshwar Kavthekar, Associate Professor, ${ }^{2}$ Dr. Ashok Annasaheb Chougule, Assistant Professor, \\ ${ }^{3}$ Dr. Anil Bapurao Kurane, Professor and HOD, all authors are affiliated with Department of Pediatrics, ${ }^{4}$ Dr. Swati \\ Saiprasad Kavthekar, Tutor, Department of Pathology, Above all authors are affiliated with D.Y. Patil Medical College \\ and Hospital Kadamwadi, Kolhapur, Maharashtra, India.
}

Corresponding Author: Dr. Ashok Annasaheb Chougule, Assistant Professor, Department of Pediatrics, D.Y.Patil Medical College and Hospital, Kadamwadi, Kolhapur, Maharashtra, India. E-mail: drashok_chougule1@yahoo.co.in

\begin{abstract}
Introduction: Skin diseases are common in children. Certain skin disorders show striking differences between sexes in incidence pattern. This study was undertaken to study the sex predominance of various skin disorders in children, aged 1 month to 5 years. Materials and Methods: 450 children aged between 1 month to 5 years attending Outpatient, Department of Pediatrics, D. Y. Patil Medical College and Hospital duringthe period of $1^{\text {st }}$ September 2017 to $31^{\text {St }}$ August 2018 included in this study. Age, sex and detailed history of all children were recorded. Skin examination was done under adequate illumination. Skin disorders were groupedunder 12 groups by clinical examination diagnosis. The data was analyzed statistically. Results: Maximum children of skin disorders belonged to age group 4-5 years and males 237 (52.66\%) outnumbered females 213(47.34\%).Highest incidence was infections 254(56.44\%). Out of infections, 95 with bacterial, 72 viral, 47 fungaland 40 parasitic infestations, males were 60(63.16\%), 50(69.45\%),12(25.54\%), $25(62.5 \%)$ and females were $35(36.84 \%), 22(30.55 \%), 35(74.46 \%), 15(37.5 \%)$ respectively. Forallergic disorders (38) and eczematouslesions (36) males were 28(73.68\%), 20(55.55\%) respectively while females were 10(26.32\%), $16(44.45 \%)$ respectively. Congenital malformations (20) had 6(30\%) males and 14(70\%) females. Papulosquamous (26) and vesiculobullous (18) lesions had 8(30.77\%) and 8(44.44\%) males and 18(69.23\%), 10(55.56\%) females respectively. Nutritional deficiency (18) and pigmentary lesions (20) were common in females $12(66.67 \%)$ and 16 (80\%) respectively. Conclusion: Bacterial, viral infections, parasitic infestations and allergic disorders showed significant sex predominance in males whereas fungal infections, congenital malformations, papulosquamous disorders, nutritional deficiency and pigmentary lesions significantly in females.
\end{abstract}

Key words: Children, Sex, Skin disorders

\section{Introduction}

Skin diseases manifesting as primary and secondary cutaneous complaints account for a significant proportion $(30 \%)$ of pediatric outpatient consultations $[1,2]$. The pattern of skin diseases is known to differ in different countries of the world and in different regions of the same country [3]. Most of the skin diseases were seen in the $1-5$ years age $(44.94 \%)$, followed by school children (29.6\%) and infants $(25.46 \%)$ [4]. Skin diseases in the pediatric age group can be transitory, chronic or recurrentand differ from those in adults in terms of diagnostic approach and management, while some of them manifest mainly or exclusively in children [5].

Manuscript received: $5^{\text {th }}$ November 2018

Reviewed: $15^{\text {th }}$ November 2018

Author Corrected: $20^{\text {th }}$ November 2018

Accepted for Publication: $25^{\text {th }}$ November 2018
Socioeconomic status, external environment, climate exposure, dietary habits and different levels of functional development of skin are the more influential factors in skin disorders in children [6]. Along with these internal and external factorsan important factor amongst these is sex of the child which in fluence the prevalence of various skin disorders. Over the decades interest is growing regarding sex differences in disease with respect to epidemiology, pathogenesis, clinical presentation and response to treatment. Certain skin diseases show striking differences between sexes in incidence pattern [7]. Since there were very few studies, this study was undertaken to study the sex predominance of various skin disorders in children aged 1 month to 5 years. 


\section{Materials and Methods}

This prospective study was conducted at D.Y. Patil Medical College and Hospital, Department of Pediatrics in Out Patient Department during the period of $1^{\text {st }}$ September 2017 to $31^{\text {st }}$ August 2018. The study was approved by Institutional Ethical committee. Informed consent from parents/guardian wasalso obtained.

450 children aged between 1 month to 5 years of various skin disorders presented with chief complaint of skin diseases or having other minor complaints but having skin manifestations were included in this study. For every child, through history was taken with particular emphasis on age, sex, family history and previous history of similar skin condition.

The skin examination was performed under adequate illumination. The skin lesions were inspected, palpated, diagnosed and classified on the basis of morphology, size, color, texture, firmness, configuration, location and distribution into following twelve groups.
1. Bacterial infections

2. Viral infections

3. Fungal (Superficial) infections

4. Parasitic infestations

5. Allergic disorders

6. Eczematous/ Dermatitis disorders

7. Congenital malformations

8. Papulosquamous disorders

9. Vesiculobullous disorders

10. Nutritional deficiency disorders

11. Pigmentary disorders

12. Miscellaneous disorders

If the diagnosis was not clear after thorough examination, relevant investigations were sent to come to the final diagnosis. All the findings were recorded and analyzed statistically by using Chi Square test where $\mathrm{p}<0.05$ was significant.

\section{Results}

In this study 450 children from the age group of 1 month to 5 years were studied. The children were placed into 5 subgroups of 1 year each as given in Table I. Maximum number of children belonged to age group 4-5 years (23.33\%) and minimum number of children belonged to age group 1 month to 1 year (16.88\%). Of them $237(52.66 \%)$ were males and $213(47.34 \%)$ were females with male to female ratio being 1:0.9.

Table-I: Age wise distribution of skin disorders in 1 month to 5 years children

\begin{tabular}{|c|c|c|c|c|c|c|}
\hline Age & Male & $\mathbf{\%}$ & Female & $\mathbf{\%}$ & Total & $\%$ \\
\hline 1month-1year & 40 & 57.14 & 30 & 42.86 & 70 & 15.55 \\
\hline$>1-2$ years & 45 & 59.21 & 31 & 40.79 & 76 & 16.88 \\
\hline$>2-3$ years & 49 & 50.51 & 48 & 49.49 & 97 & 21.55 \\
\hline$>3-4$ years & 48 & 47.05 & 54 & 52.95 & 102 & 22.65 \\
\hline$>4-5$ years & 55 & 52.38 & 50 & 47.62 & 105 & 23.33 \\
\hline Total & $\mathbf{2 3 7}$ & $\mathbf{5 2 . 6 6}$ & $\mathbf{2 1 3}$ & $\mathbf{4 7 . 3 4}$ & $\mathbf{4 5 0}$ & $\mathbf{1 0 0}$ \\
\hline
\end{tabular}

Out of 450 children having skin disorders, maximum incidence was infections $254 / 450(56.44 \%)$. Out of infections, 95(21.1\%) children were ofbacterial infections whichwere seen in 60(63.16\%) of males and 35(36.84\%) females. Viral infections were seen in $72(16 \%)$ children which had 50(69.45\%) were males and $22(30.55 \%)$ females. Fungal infections were seen in $47(10.44 \%)$ children which had $12(25.54 \%)$ males and 35(74.46\%) females. 40 (8.88\%) children of parasitic infestations included 25(62.5\%) males and 15(37.5\%) females.[TableII] [Figure I]

Allergic disorders were seen in $38(8.44 \%)$ children comprised of 28(73.68\%) males and 10(26.32\%) females.36 (8\%) cases of eczematous skin disorders were distributed in 20(55.55\%) males and 16(44.45\%) females. Congenital malformations were seen in 20(4.44\%) children which had 6(30\%) males and 14(70\%) females. 26(5.77\%) Children with papulosquamous disorders were distributed in $8(30.77 \%)$ and $18(69.23 \%)$ females. Vesiculobullousdisorders were seen in $18(4 \%)$ children out of which $8(44.44 \%)$ males and $10(55.56 \%)$ females. $18(4 \%)$ children with nutritional deficiency disorders included 6(33.33\%) males and 12(66.67\%) females.Pigmentary lesions were seen in 20(4.44\%) cases in which $4(20 \%)$ were males and 16(80\%) were females. Miscellaneous disorders showed equivocal sex trend. [Table II] [Figure I] 
Letter to Editor

Table II: Clinical Pattern of various skin disorders in children aged 1 month to 5 years

\begin{tabular}{|c|c|c|c|c|c|c|c|c|}
\hline Sr.No & Skin Disorder & Male & $\%$ & Female & $\%$ & Total & $\%$ & P value \\
\hline 1 & Bacterial Infection & 60 & 63.16 & 35 & 36.84 & 95 & 21.1 & $<0.05$ \\
\hline 2 & Viral Infection & 50 & 69.45 & 22 & 30.55 & 72 & 16 & $<0.05$ \\
\hline 3 & Fungal Infection & 12 & 25.54 & 35 & 74.46 & 47 & 10.44 & $<0.05$ \\
\hline 4 & Parasitic Infestations & 25 & 62.5 & 15 & 37.5 & 40 & 8.88 & $<0.05$ \\
\hline 5 & Allergic Disorders & 28 & 73.68 & 10 & 26.32 & 38 & 8.44 & $<0.05$ \\
\hline 6 & Eczematous Disorders & 20 & 55.55 & 16 & 44.45 & 36 & 8 & $>0.05$ \\
\hline 7 & Congenital Malformations & 6 & 30 & 14 & 70 & 20 & 4.44 & $<0.05$ \\
\hline 8 & Papulosquamous Disorders & 8 & 30.76 & 18 & 69.23 & 26 & 5.77 & $<0.05$ \\
\hline 9 & Vesiculobullous Disorders & 8 & 44.44 & 10 & 55.56 & 18 & 4 & $>0.05$ \\
\hline 10 & $\begin{array}{l}\text { Nutritional Deficiency } \\
\text { disorders }\end{array}$ & 6 & 33.33 & 12 & 66.67 & 18 & 4 & $<0.05$ \\
\hline 11 & Pigmentary lesions & 4 & 20 & 16 & 80 & 20 & 4.44 & $<0.05$ \\
\hline \multirow[t]{2}{*}{12} & Miscellaneous Disorders & 10 & 50 & 10 & 50 & 20 & 4.44 & $>0.05$ \\
\hline & Total & 237 & 52.66 & 213 & 47.34 & 450 & 100 & $>0.05$ \\
\hline
\end{tabular}

$(\mathrm{p}<0.05$ Significant; $\mathrm{p}>0.05$ Non significant $)$

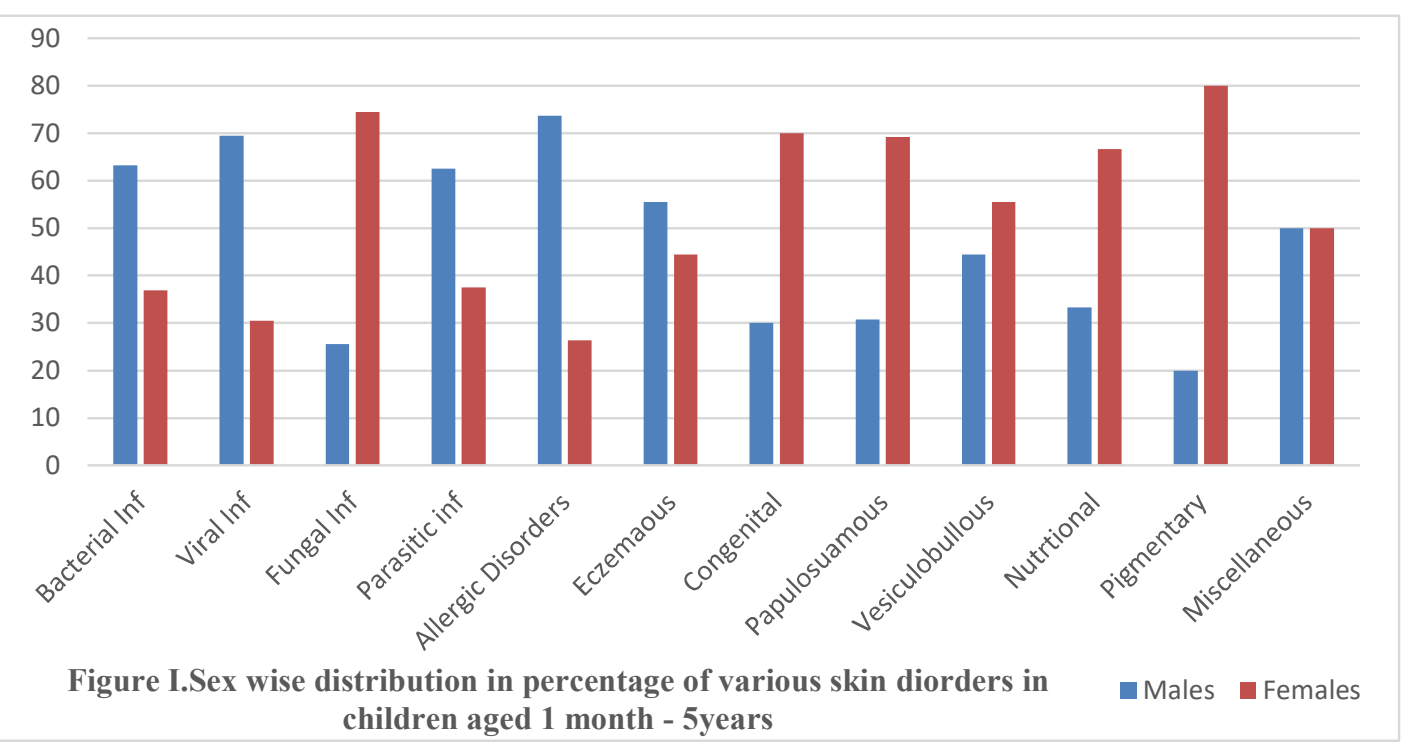

In this study total males outnumbered females but was not statistically significant $(\mathrm{p}>0.05)$. Bacterial, viral infections and parasitic infestations, allergic disorders showed statistically significant sex predominance in males. $(\mathrm{p}<0.05)$, whereas superficial fungal infections, congenital malformations, paulosquamous disorders, nutritional deficiency disorders and pigmentary lesions showed significant sex predominance in females. $(\mathrm{p}<0.05)$. Eczematous disorders and vesiculobullous disorders did not show statistically significant sex predominance $(\mathrm{p}>0.05)$

\section{Discussion}

Sex has a major impact on outcome from a range of infectious diseases to skin diseases, starting from the beginning of life. Overall morbidity and mortality rates are higher in males than in females throughout life [8]. Skin disorders in children are encountered frequently and their characterization is essential for the preparation of academic, research and health plans. The evaluation for skin disorders are an important component of primary health care practice for all including children [9]. We planned this study as a detailed knowledge 
Letter to Editor

about the pattern and sex in pediatric skin disorders in our area will help us in implementing essential changes in health education, disease control and prevention. In our study, total males outnumbered females but was not statistically significant. Bisht JS et al [10], Awal G etal [11] and Sardana $\mathrm{k}$ et al [12] observedmale predominance while few studies had female predominance $[13,14,15]$.

Children between 4- 5 years were more affected with skin disorders similar results found by Bisht $\mathrm{J} S$ etal [10]. Awal $\mathrm{G}$ et al [11] found children upto 1 year were more affected. The most common skin disorder in our study was infections out of which bacterial was commonest followed by viral, fungaland parasitic infestations. Bacterial, viral infections and parasitic infestations were significantly higher in males whereas fungal infectionsin females. Bisht $J \mathrm{~S}$ et al [10] etal did not found statistically significant difference in male and female children as far as infections and infestations were concerned.

Awal $\mathrm{G}$ etal[11] found $26.3 \%$ were males and $14.8 \%$ females for infective dermatoses. Mostafa FF et al [15] found significant sex predominance for females for infestations. In humans, females reportedly mount stronger humoral and cellular immune responses to infection or antigenic stimulation than do males [16]. Allergic disorders were also showed significant sex predominance in males, similar to Awal G et al [11].

Congenital malformations, papulosquamous disorders, nutritional deficiency disorders and pigmentary lesions showed significant female sex predominance in our study. The most common amongst congenital malformations were hemangiomas while for nutritional deficiency disorders it was phrynoderma.

Bisht JS et al [10] and Awal G et al [11] found pigmentary lesions significantly higher in females while Mostafa FF et al [15] found female predominance for papulosquamous disorders. Miscellaneous skin disorders constituted cases of tuberous sclerosis, milia, and erythema multiforme.

The reasons for underlying sex-based disparities in the incidence of skin and skin related disease remain largely unknown but are likely multifactorial.

Factors that ought to be considered include 1) sex difference in the structure and function of skin; 2) genetic predisposition; 3) effects of sex hormones; 4) race / ethnicity; 5) socio culture behavior; and 6) environ-mental or geographic factors $[17,18,19]$.
The limitation of this study was, it was a single center study. A large prospective multicenter study needs to be conducted to know more sex predominance inpediatric skin disorders.

\section{Conclusion}

Bacterial, viral infections, parasitic infestations and allergic disorders showed significant sex predominance in males whereas fungal infections, congenital malformations, papulosquamous disorders, nutritional deficiency and pigmentary lesions showed significant sex predominance in females.

Contributors: SK, AC: designed the study, collected and analyzed the data and drafted the manuscript. AK: supervision of work and analyzed the data.

SSK: literature search and drafted the manuscript. AK will act as the guarantor. All authors approved the final version of manuscript.

Funding: Nil, Conflict of interest: None initiated, Perission from IRB: Yes

\section{References}

1. Thappa DM. Common skin problems. Indian $\mathrm{J}$ Pediatr. 2002 Aug;69(8):701-6.

2. Federman DG, Reid M, Feldman SR, et al. The primary care provider and the care of skin disease: the patient's perspective. Arch Dermatol. 2001 Jan;137(1): 25-9.

3. Sacchidanand S, Sahana MS, Asha GS, Shilpa K. Pattern of pediatric dermatoses at a referral centre. Indian J Pediatr. 2014 Apr;81(4):375-80. doi: 10.1007/s 12098-012-0904-8. Epub 2012 Nov 6.

4. Jain N, Khandpur S. Pediatric dermatoses in India. Indian J Dermatol VenereolLeprol. 2010 Sep-Oct; 76(5): 451-4. doi: 10.4103/0378-6323.69034.

5. Vakirlis E, Theodosiou G, Apalla Z, A retrospective epidemiological study of skin diseases among pediatric population attending a tertiary dermatology referral center in Northern Greece. Clin Cosmet Investig Dermatol. 2017 Apr 3;10:99-104. doi: 10.2147/CCID. S130126. eCollection 2017.

6. Banerjee S, Gangopadhyay DN, Jana S, Chanda M. Seasonal variation in pediatric dermatoses. Indian $\mathrm{J}$ Dermatol. 2010; 55(1):44-6. doi: 10.4103/0019-5154. 60351. 
Letter to Editor

7. Andersen LK, Davis Mark DP. Sex differences in the incidence of skin and skin related diseases in Olmsted Country, Minnesota, United States, and a comparison with other rates published worldwide. Int J Dermatol. September 2016;55(9):939-55

8. Lozano R, Naghavi M, Foreman K, Global and regional mortality from 235 causes of death for 20 age groups in 1990 and 2010: a systematic analysis for the Global Burden of Disease Study 2010. Lancet. 2012 Dec 15;380(9859):2095-128. doi: 10.1016/S0140-6736 (12) 61728-0.

9. Hayden GF. Skin diseases encountered in a pediatric clinic. A one-year prospective study. Am J Dis Child. 1985 Jan;139(1):36-8.

10.Bisht JS, Rana SK, Kumari N, Aggarwal B, Mehta A, Singh A. Pattern of dermatoses in preschool children in a teaching hospital in Uttarakhand, India. Indian journal of pediatric dermatology 2015 Oct-Dec;16(4): 198-202

11. Awal G, Singh SP, Sharma S, Kaur J. Spectrum and pattern of pediatric dermatoses in under five population in a tertiary care center. International Journal of Research in Dermatology. 2016 Oct-Dec; 2(4): 69-76

12. Sardana K, Mahajan S, Sarkar R, et al. The spectrum of skin disease among Indian children. Pediatr Dermatol. 2009 Jan-Feb;26(1):6-13. doi: 10 1111/j. 1525-1470.2008.00814.x.
13. Reddy VS, Thyvalappil A, Sreenivasan A, Sudhamani B, Sridharan R. Study of clinical spectrum of pediatric dermatoses in patients attending a tertiary care center in North Kerala. Indian journal of pediatric dermatology. 2016 Oct-Dec;17(4):267-72

14. Karthikeyan K, Thappa DM, Jeevankumar B. et al. Pattern of pediatric dermatoses in a referral center in South India. Indian Pediatr. 2004 Apr;41(4):373-7.

15. Mostafa FF, Hasan Hamid AA. Prevalence of skin diseases among infants and children in AI Sharqia Governorate, Egypt. Egyptian Dermatology online Journal. 2012. June;1(4):1-14

16. Fish EN. The X-files in immunity: sex-based differences predispose immune responses. Nat Rev Immunol. 2008 Sep; 8(9):737-44. doi: 10.1038/nri2394. DOI:10.1038/nri2394

17. Tamir E, Brenner S. Gender differences in collagen diseases. Skinmed. 2003 Mar-Apr;2(2):113-7.

18. Dao H Jr, Kazin RA. Gender differences in skin: a review of the literature.Gend Med.2007Dec;4(4):308-28

19. Chen W, Mempel M, Traidl-Hofmann C, et al. Gender aspects in skin diseases. J Eur Acad Dermatol Venereol. 2010 Dec; 24(12):1378-85. doi: 10.1111/j. 1468- 3083. 2010.03668.x.

\section{How to cite this article?}

Kavthekar S.O, Chougule A.A, Kurane A.B, Kavthekar S.S. Study of sex predominance in skin disorders in children aged 1 month to 5 years.Int J Pediatr Res. 2018;5(11):564-568.doi:10.17511/ijpr.2018.i11.03. 